\title{
Simulation of Future Land Use/Cover Changes in Zanjan City, Iran Based on the CA-Markov Model and the Assessment of Its Impact on Surroundings Rural Settlements
}

\author{
P. Jalerajabi and R. Ahmadian
}

\begin{abstract}
Urban growth and land use systems are complex systems that mainly grow from the bottom up so it is difficult or even impossible to represent these processes by using top-down GIS functionality. Instead of using traditional top-down models such as GIS, recent studies have shown that these complex natural systems can be effectively simulated by using a number of bottom-up models, such as cellular automaton models (CAs). In this study Using Zanjan area, Iran as an example, future land use/cover changes up to 2041 were simulated based on a Markov-cellular automata model that integrates Markovian transition probabilities computed from satellite-derived land use/cover maps and a cellular automata spatial filter. In this study Calibration of the model was performed by using of a new statistical method based on regression analysis and correlation coefficient. Three separate models including CA model, Markov model and Markov-cellular automata model was calibrated. The Markov-cellular automata's overall simulation success is $\mathbf{7 1 \%}$ that is very acceptable in urban predictions. Future land use/cover simulations indicated that if the current land use/cover trends continue in the study area rural settlements that are located near the Zanjan city such as Payeen koh and Do asb will become new suburban areas of the city and their valuable agriculture lands change to urban built-up area.
\end{abstract}

Index Terms - Calibration, CA-markov model, complex system, land use/cover changes, simulation.

\section{INTRODUCTION}

Land use changes have been considered among the biggest challenges for humankind in the twenty-first century [1]. There are numerous studies on the detection of land use change using remote sensing and geographic information system (GIS). However, there is a general lack of studies on the simulation of land use changes because of their complexities [2]. Recent studies have shown that these complex natural systems can be effectively simulated by using a number of bottom-up models [1]. A robust bottom-up approach commonly used in the simulation for land use change (LUC) is based on Markov-cellular automata model and the GIS framework [3], [4]. GIS and remote sensing data can be efficiently incorporated in this model [5]. Both cellular automata (CA) and the Markov model have great advantages

Manuscript received October 25, 2012; revised January 28, 2013.

P. Jalerajabi is with the Department of urban Planning, Science and research branch, Islamic Azad University, Tehran, Iran (e-mail: parvaneh.jalerajabi@gmail.com)

R. Ahmadian is with the Department of urban design and urban Planning, Islamic Azad University, Zanjan Branch, Zanjan, Iran (e-mail: rahmadian@ yahoo.com). in the study on land use changes, while both of them have respective disadvantages [6]. The Markov model for land use changes only produces the prediction of land use categories without spatial details [2]. The CA model with powerful spatial computing can be used to simulate the spatial variation of the system effectively. The CA-Markov model absorbs the benefits from the time series and spatial predictions of the Markov and CA theory, and it can be used to carry out the Spatial-Temporal Pattern simulation [6].

Previous studies have attempted to simulate land use changes pattern by using CA-Markov model. Sang et el.(2011) have used this model for simulating of land use spatial pattern of towns and villages [6], Kamusoko et el.(2009) used a combined method of Markov chain and cellular automat model in Simulation of future land use/cover changes in the Bindura district[5]. Both of these studies concluded that the CA-Markov model gives good results for detecting changes in future. But the calibration of model is neglected in these and other studies. Despite the recognition of Cellular Automata (CA) as a flexible and powerful tool for LUC simulation, the calibration of CA had been largely heuristic [7]. Calibration of CA models is needed to ensure that the simulation can generate the results close to the reality [2].

The objective of this study is to simulate future land use/cover changes (up to 2041) in the Zanjan area, Iran. For this purpose The CA-Markov model combined with GIS is selected. The Zanjan area is selected because in this Area considerable land use changes have occurred due to urban developments, rural developments, and industrial developments in the east and north-east where rural settlements are located and that major changes in the crop pattern are ongoing. Moreover, the study suggests the need to examine the result of CA-Markov model through applying a new calibration method based on regression analysis and correlation coefficient.

\section{STUDY AREA AND DATA}

\section{A. Study Area}

The city of Zanjan, capital of Zanjan Province is located between $36^{\circ} 38^{\prime} 56^{\prime \prime}$ to $36^{\circ} 42^{\prime \prime} 22^{\prime \prime} \mathrm{N}$ and $48^{\circ} 25^{\prime} 42^{\prime \prime}$ to $48^{\circ} 33^{\prime} 05^{\prime \prime} \mathrm{E}$. The study area covers Zanjan city and its surrounding area with 34330.95 hectares that four rural settlements including sayan, Gavazang, Payeen koh and Do asb are located in this area. Zanjan population in 1986 was about 215,458 people and its population has been reached to 
386,851 people in 2011 , the population growth rate in this period was about 2.2 percent. In this selected Area considerable land use changes have occurred. These changes were assessed in this research using multi temporal satellite imagery and GIS and the future changes was simulated using CA-Markov model combined with GIS.

\section{B. Data Source and Processing}

The main data sources are digital land use data including Landsat TM images captured in 1984, 1990, 2000 and 2011, Land use maps and land use change maps in 1984, 1990, 2000 and 2011 that were extracted from processing of multi temporal satellite images. The fuzzy adaptive resonance theory (Fuzzy ARTMAP) is employed for image classification and producing land use maps. The digital map data for the study contain seven classes: 1) built-up area, 2) orchards, 3) irrigated agriculture land, 4) dry farming, 5) water, 6) regolith and waste land and 7) pastures. The detailed processing of multi temporal satellite images procedure is as follows: (1) First, 741 (RGB) color composites of Landsat images were prepared (2) Then, training areas were selected for 7 land cover classes. These training areas were determined, referring to aerial photographs and GIS thematic maps (3) to assess the accuracy of classification, topographic maps and aerial photos were employed. Overall accuracy was estimated to be around $93 . \%$.

\section{RESEARCH METHODS}

\section{A. Markov Model}

The Markov model is a theory based on the process of the formation of Markov random process systems for the prediction and optimal control theory method [6]. Markov chain method analyses a pair of land cover images and outputs a transition probability matrix, a transition area matrix, and a set of conditional probability images. The transition probability matrix shows the probability that one landuse class will change to the others. The transition area matrix tells the number of pixels that are expected to change from one class to the others over the specified period. The conditional probability images illustrate the probability that each land cover type would be found after a specific time passes [8]. The Markov chain analysis was used to compute transition probabilities based on the Landsat derived land use/cover maps for 1984 and 2011.

\section{B. CA-Markov Model}

The second method is Combination of Cellular Automata and Markov Chain. With the traditional Markov model it is difficult to predict the spatial pattern of land use changes. The CA model with powerful spatial computing can be used to simulate the spatial variation of the system effectively [5]. The CA-Markov model can achieve better simulation for temporal and spatial patterns of land use changes in quantity and space [6].

\section{Regression Analysis and Correlation Coefficient}

Calibration of CA models is needed to ensure that the simulation can generate the results close to the reality. There are two major types of calibration methods for CA simulation. One type is based on statistical methods. Another type of calibration is based on trial and error approaches [5]. This paper presents a new statistical calibration method based on regression analysis and correlation coefficient. Regression analysis involves identifying the relationship between a dependent variable and one or more independent variables. A model of the relationship is hypothesized, and estimates of the parameter values are used to develop an estimated regression equation. Various tests are then employed to determine if the model is satisfactory. If the model is deemed satisfactory, the estimated regression equation can be used to predict the value of the dependent variable given values for the independent variables. Correlation and regression analysis are related in the sense that both deal with relationships among variables. The correlation coefficient is a measure of linear association between two variables. Values of the correlation coefficient are always between -1 and +1 . A correlation coefficient of +1 indicates that two variables are perfectly related in a positive linear sense; a correlation coefficient of -1 indicates that two variables are perfectly related in a negative linear sense, and a correlation coefficient of 0 indicates that there is no linear relationship between the two variables [9], [10].

The CA-Markov model to simulate land use changes has been put into use in this paper. First 1984 and 2011 land use map was analyzed with Markov Chain. Then, combined method of Cellular Automata and Markov Chain was used for forecasting land use change in 2021, 2031, 2041. The specific process is as follows:

1) Determining the transition rules With Markov chain analysis on the basis of the preceding state. The calculated transition probability matrix in this stage will serve as the transformation rules to put CA-Markov model simulations

2) Determining CA filters. The standard $5 \times 5$ contiguity filter is used as the neighborhood definition in this study. That is, each cellular center is surrounded by a matrix space which is composed by $5 \times 5$ cellular to impact the cellular changes significantly.

3) Determining the starting point and the CA number of iterations. The study takes the year 2011 as a starting point. The number of CA iterations is selected at 10 in order to simulate the landscape spatial pattern for the study area in 2021, 2031, and 2041.

4) Calibration of the model. Regression analysis and correlation coefficient were applied to calibrate the applying model. The Results of calibration show that in case study area CA-Markov model has the greatest success in predicting land use/cover changes that respectively 71 percent.

\section{RESUlTS AND ANALYSIS}

\section{A. Fuzzy ARTMAP Classification and Land Use Changes}

The Fuzzy ARTMAP classification results for the four different times revealed that the land use of the target area has changed about $25 \%$ during the period of 1984-2011. Table I shows the estimated land use transitions based on the 
comparison of the classification results for the 1984 and 2011 images .The results show that built -up area changed from 2855 hectare in 1984 to 7377 hectare in 2011. The Results of Land use changes analysis show that in case study area dry farming and regolith and waste land have most change to built-up area that respectively 1987 and 2521 hectares. Also water body and orchards have minimum changes to built-up area that respectively 32 and 26 hectares. Table II shows land use transition to built-up area in case study area during 1984-2011 and Fig. 1 shows the areas that have changed to built-up in the period of 1984-2011. As is indicated in Fig. 1 These changes have led to merger of two of the rural settlements including Sayan and Gavazang in Zanjan city.

TABLE I: ESTIMATED LAND USE TRANSITIONS IN ZANJAN AREA BETWEEN 1984 AND 2011 (HeCTARE)

\begin{tabular}{|c|c|c|c|c|c|c|c|c|c|}
\hline Class & & 1 & 2 & 3 & 4 & 5 & 6 & 7 & $\sum$ \\
\hline 1 & Built- Up & 2332 & - & - & - & - & 357 & 165 & 2855 \\
\hline 2 & Orchards & 32 & 190 & 34 & 77 & - & 13 & 48 & 393 \\
\hline 3 & Irrigated Agriculture & 245 & 518 & 174 & 603 & 0 & 65 & 336 & 1942 \\
\hline 4 & Dry Farming & 1987 & 90 & 179 & 3823 & 9 & 2983 & 944 & 10014 \\
\hline 5 & Water & 26 & - & 0 & 2 & - & 16 & 4 & 49 \\
\hline 6 & $\begin{array}{l}\text { Regolith \& } \\
\text { Waste land }\end{array}$ & 2521 & - & 53 & 2026 & 21 & 4272 & 3389 & 12283 \\
\hline 7 & Pastures & 593 & 85 & 57 & 792 & 8 & 1040 & 4218 & 6795 \\
\hline$\sum$ & & $\begin{array}{c}7736 \\
23\end{array}$ & $\begin{array}{c}882 \\
3\end{array}$ & $\begin{array}{c}498 \\
1\end{array}$ & $\begin{array}{c}7323 \\
21\end{array}$ & $\begin{array}{c}38 \\
0\end{array}$ & $\begin{array}{c}8747 \\
25\end{array}$ & $\begin{array}{c}9105 \\
27\end{array}$ & 34331 \\
\hline
\end{tabular}

TABLE II: ESTIMATED LAND USE TRANSITIONS TO BUILD-UP AREA IN CASE STUDY AREA BETWEEN 1984 AND 2011 (HECTARE).

\begin{tabular}{cccccc} 
Class & Landuse Type & 1984 & 2011 & $\begin{array}{c}\text { Change to } \\
\text { built up } \\
1984-2011\end{array}$ & $\begin{array}{c}\text { Percentage } \\
\text { change to } \\
\text { built-up }\end{array}$ \\
\hline 2 & Orchards & 393 & 966 & 32 & 0.41 \\
3 & $\begin{array}{c}\text { Irrigated } \\
\text { Agriculture }\end{array}$ & 1942 & 525 & 245 & 3.17 \\
4 & $\begin{array}{c}\text { Dry Farming } \\
5\end{array}$ & 10014 & 7603 & 1987 & 25.68 \\
6 & Water & 49 & 40 & 26 & 0.34 \\
7 & $\begin{array}{c}\text { Regolith \& } \\
\text { Waste land }\end{array}$ & 12283 & 8716 & 2521 & 32.58 \\
& Pastures & 6795 & 9105 & 593 & 7.67
\end{tabular}

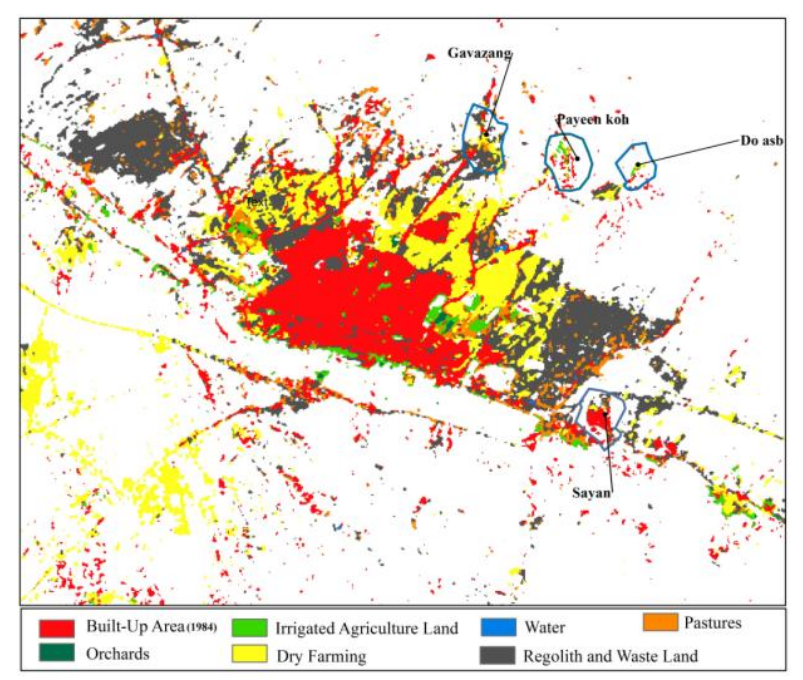

Fig. 1. The areas that have changed to built-up in the period of 1984-2011.

\section{B. Model Application}

The CA-Markov module in IDRISI integrates the functions of cellular automaton filter and Markov processes, using conversion tables and conditional probability of the conversion map to predict the states of land use changes. In order to implement the Markov-cellular automata model in the study area and predict the trends of land use changes, using algorithms available in IDRISI Taiga, first 1984 and 2011 land use map were analyzed with Markov Chain and transition probabilities using Markov chain analysis was computed. Table III shows the probability of land use changes based on Markov Chain in the period of 2011-2041 and Table IV shows the areas that will have changed by 2041 .

Then, CA filter was used for spatial allocation of simulation land use. Land use pattern changes in 2021, 2031 and 2041 were predicted using a CA-Markov model based on Zanjan Area of Iran (Figs. 2, 3 and 4).

Finally, to ensure that the simulation has generated the results close to the reality, calibration was used. First, the land use map of 1991 as an initial state and the land use map of 2000 as the target state were used. Then prediction was performed for 2011 based on CA-Markov model. In the next stage the simulated land use/cover maps for 2011 was compared with the actual satellite-derived land use/cover maps. In this comparison correlation coefficient between results of simulation and actual conditions was calculated. This calibration method was performed on three types of models including CA model, Markov model and CA-Markov model. The Markov-cellular automata's overall simulation success is $71 \%$ for 2011 and shows the greatest correlation to reality among these models (Fig. 5, 6).

According to the results (Fig. 2, 3 and 4 and Table III and IV), built -up areas increase from 7377 hectare in 2011 to 9689.4 hectares in 2041 and the probability change of Orchards and dry farming to built-up area are highest in comparing with other land use types to built-up area. The area converted to construction land mainly encompassed rural settlements. These changes of land use types will have led the merger of rural settlements into the body the city by 2041. As is indicated in Fig. 2, 3 and 4 Do asb and Payeen koh have gradually merged in the city in result of land use/ cover changes. 


\begin{tabular}{ccccccccc}
\hline \hline Class & 1 & 2 & 3 & 4 & 5 & 6 & 7 & $\sum$ \\
\hline 1 & 0.2116 & 0.0000 & 0.0000 & 0.0290 & 0.0005 & 0.0328 & 0.0082 & 0.2822 \\
2 & 0.0016 & 0.0237 & 0.0019 & 0.0001 & 0.0000 & 0.0000 & 0.0001 & 0.0273 \\
3 & 0.0000 & 0.0011 & 0.0110 & 0.0007 & 0.0000 & 0.0000 & 0.0001 & 0.0129 \\
4 & 0.0003 & 0.0033 & 0.0021 & 0.1657 & 0.0000 & 0.0038 & 0.0078 & 0.1829 \\
5 & 0.0000 & 0.0000 & 0.0000 & 0.0001 & 0.0006 & 0.0001 & 0.0002 & 0.0010 \\
6 & 0.0013 & 0.0001 & 0.0001 & 0.0244 & 0.0000 & 0.1871 & 0.0044 & 0.2175 \\
7 & 0.0000 & 0.0001 & 0.0002 & 0.0015 & 0.0000 & 0.0300 & 0.2444 & 0.2762 \\
$\Sigma$ & 0.2148 & 0.283 & 0.153 & 0.2215 & 0.0011 & 0.2538 & 0.2652 & 1.0000
\end{tabular}

TABLE IV: The Results of PREdiction of LAND Use Simulation in 2041 By the Combinat Ion of Cellular Automata and Markov Chain

\begin{tabular}{|c|c|c|c|c|c|c|c|c|}
\hline Class & 1 & 2 & 3 & 4 & 5 & 6 & 7 & $\sum$ \\
\hline 1 & 7265.52 & 0.09 & 1.26 & 995.76 & 18.72 & 1125.36 & 282.69 & 9689.4 \\
\hline 2 & 56.16 & 811.98 & 63.54 & 3.15 & 0 & 0 & 3.96 & 938.79 \\
\hline 3 & .99 & 36.36 & 378.54 & 23.67 & 0 & 0 & 2.61 & 442.17 \\
\hline 4 & 9.27 & 112.59 & 71.64 & 5687.19 & 0 & 131.76 & 266.31 & 6278.76 \\
\hline 5 & 0.36 & 0 & 0 & 4.23 & 20.43 & 3.96 & 6.12 & 35.1 \\
\hline 6 & 45 & 2.07 & 4.77 & 837.9 & 0.09 & 6424.47 & 151.56 & 7465.86 \\
\hline 7 & 0 & 2.7 & 5.22 & 50.76 & 0.36 & 1030.14 & 8391.69 & 9480.87 \\
\hline$\sum$ & 7377.3 & 965.79 & 524.97 & 7602.66 & 39.6 & 8715.69 & 9104.94 & 34330.95 \\
\hline
\end{tabular}

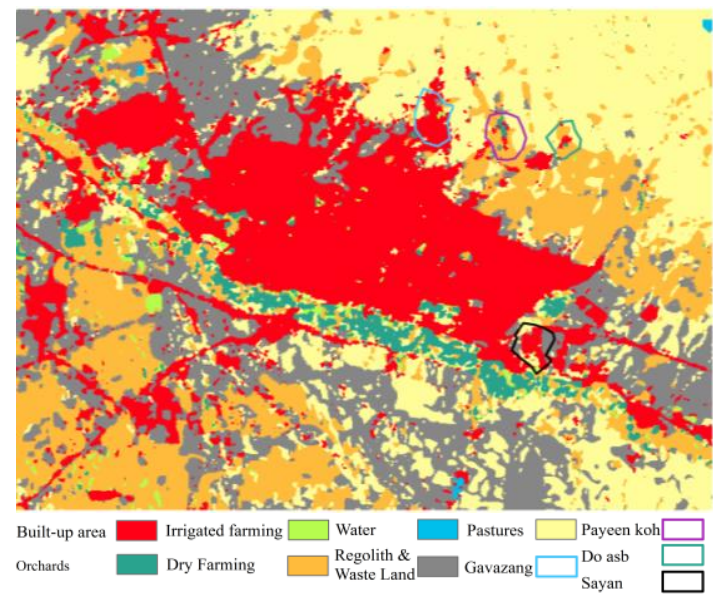

Fig. 2. Simulated result of land-use change in 2021 by the combination of cellular automata and markov chain.

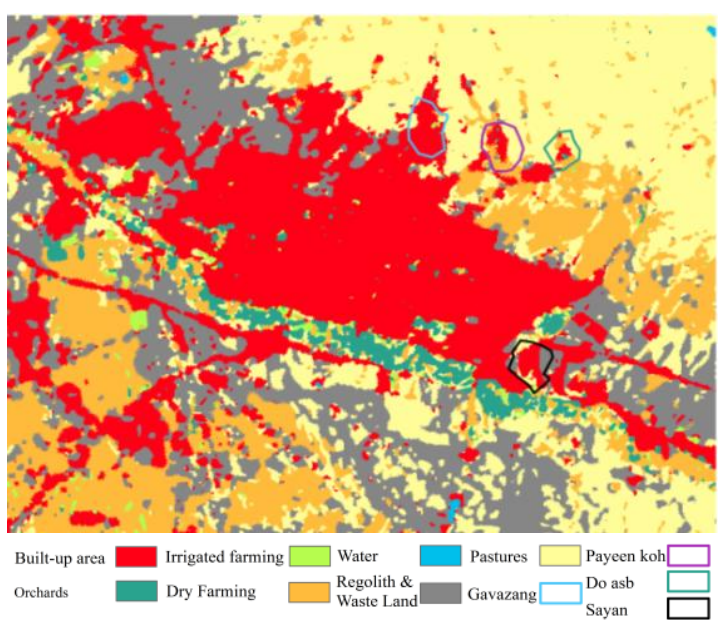

Fig. 4. Simulated result of land-use change in 2041 by the combination of cellular automata and markov chain.

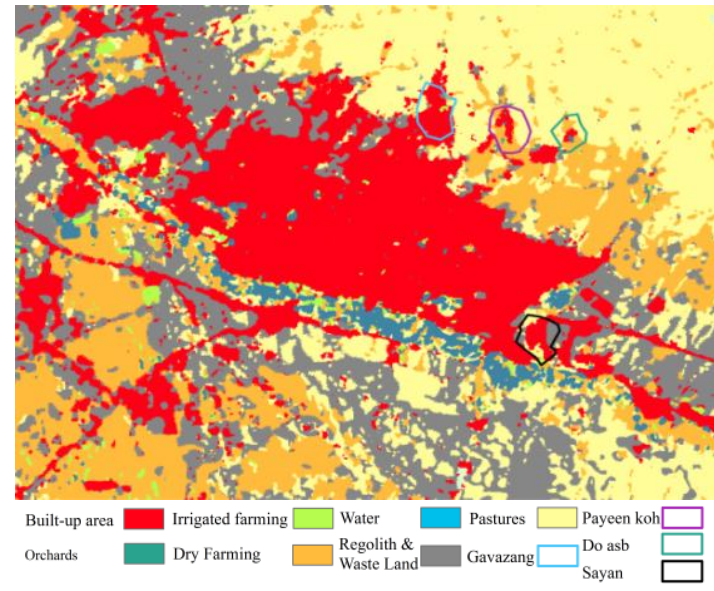

Fig. 3. Simulated result of land-use change in 2031 by the combination of cellular automata and markov chain.

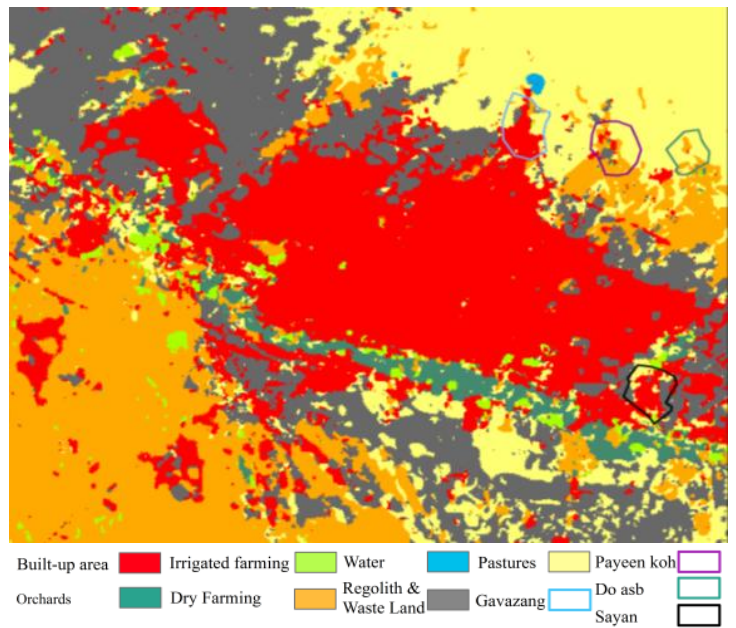

Fig. 5. The calibration result map in 2011 by using of regression analysis and correlation coefficient. 


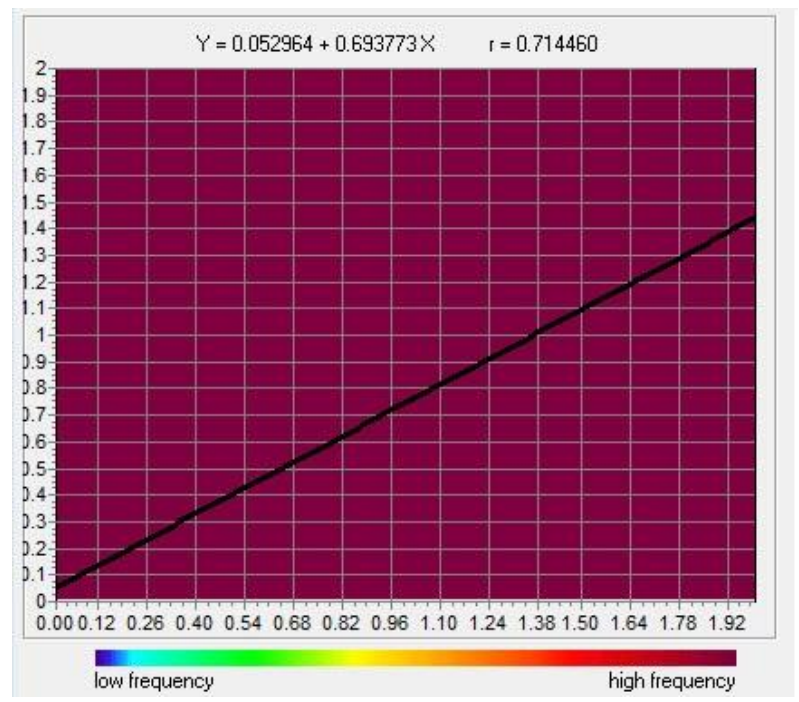

Fig. 6: The calibration results of CA-Markov Model: Correlation coefficient between X, Y: 0.714460 Regression parameters:

X variable: Land use/cover map of 2011

Y variable: Simulated Land use/cover map of 2011

\section{CONCLUSION}

Using satellite-derived land use/cover maps (1984, 1990, 2000 and 2011) Markov-cellular automata model that combines the Markov chain analysis and cellular automata models simulated successfully land use/cover changes in the Zanjan area. The model's overall simulation success was $71 \%$ for the 2011 simulated land use/cover map. This study shows that CA-Markove has a great ability in predicting and simulating of land use changes rather than CA or Markov model. Future land use/cover simulations up to 2041 indicated that if the current land use/cover trends continue without holistic sustainable development policies involving the participation of all the stakeholders in the study area, severe land degradation will occur, with serios threats to rural sustainability.

The simulated future land use/cover maps produced in this study provide a strategic guide to rural land use planning. Furthermore, the simulated future land use/cover maps can serve as an early warning system of the future effects of land use/cover changes.

While the model has successfully simulated future land use/cover changes, policies that influence the behaviour of local farmers have not been considered. Thus, future study should attempt to include policy related factors in the simulation of future land use/cover changes.

\section{REFERENCES}

[1] X. Li, "Emergence of bottom-up models as a tool for landscape simulation and planning," Landscape and Urban Planning, vol. 100, pp. 393-395, 2011.

[2] X. Li and A. G-O. Yeh, "Neural-network-based cellular automata for simulating multiple land use changes using GIS," Geographical Information Science, vol. 16, no. 4, pp. 323-343, Nov. 2010.

[3] V. Kocabas and S. Dragicevic, "Assessing cellular automata model behaviour using a sensitivity analysis approach," Computers, Environment and Urban Systems, vol. 30, pp. 921-953, 2006.

[4] B. C. Pijanowski, D. G. Brown, and G. Manik, "Using neural nets and GIS to forecast land use changes: a land transformation model," Computers, Environment and Urban Systems, vol. 26, no. 6, pp. 553-575, 2002.

[5] C. Kamusoko, M. Aniya, B. Adi, and M. Manjoro, "Rural sustainability under threat in Zimbabwe - Simulation of future land use/cover changes in the Bindura district based on the Markov-cellular automata model, " Applied Geography, vol. 29, pp. 435-447, 2009.

[6] L. Sang, CH. Zhang, J. Yang, D. Zha, and W. Yun, "Simulation of land use spatial pattern of towns and villages based on CA-Markov model," Mathematical and Computer Modelling, vol. 54, pp. 938-943, 2011.

[7] F. Wu, "Calibration of stochastic cellular automata: the application to rural-urban land conversions," Geographical Information Science, vol. 16, pp. 795-818, Ap. 2002.

[8] M. Ahadnejad reveshty, "The assessment and predicting of land use changes to urban area using multi-temporal satellite imagery and GIS: a case study on Zanjan, Iran (1984-2011)," Geographic Information System, vol. 2, pp. 298-305, October 2011.

[9] S. Chatterjee and A. Hadi, Regression analysis by example, 4th ed

[10] A. Cochocki and R. Unbehauen, Neural Networks for Optimization and Signal Processing, 1st ed., Chichester, U.K.: Wiley, 2006, pp. 20-25.

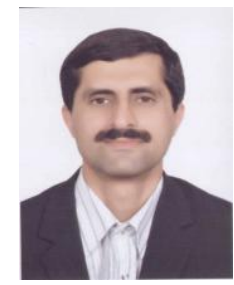

Reza Ahmadian was born on September 14, 1966 in Kerman, Iran. He received his Bachelor of Art degree in social planning from University of Allame Tabatabaiee in 1988. He undertook the Master of Art (M.A.) course (urban and regional planing) in September, 1993 and earned his M.A. degree in 1994. He started his doctoral research in April, 1999 and got his Ph.D degree from science and research branch, Islamic Azad University of Tehran in 2002. He has been involved in "urban systems engineering". He has Undertaken the preparation of different urban plans and has been the administrative manager of different urban master plans such as master plan of Yazd, Meibod, Ardakan, sanandaj, and other cities of Iran. He is the head of urban planning department of Maab consulting engineers firm now. He is also Assistant Professor, Department of Urban Design and Planning, Islamic Azad University, Zanjan Branch, 2007-present; and has published many scientific papers in different journals and conferences such as" Providing the zoning model of land use in researching about coastal region of Iran(ICZM),EMECS.8, shanghai university" and " Planning of Rural Ecomuseums in Forest Ruralsin Mazandaran Province, Iran". 